\title{
DA EVOLUÇÃO CONSTITUCIONAL PROJETADA NA TUTELA AO MEIO AMBIENTE ${ }^{1}$
}

Ariel Augusto Pinheiro dos SANTOS ${ }^{1}$

Magno Federici GOMES ${ }^{2}$

\begin{abstract}
${ }^{1}$ Mestre em Direito pela Escola Superior Dom Helder Câmara. Graduado em Direito pela Escola Superior Dom Helder Câmara. Graduando em Gestão Pública pela Universidade Federal de Minas Gerais. Currículo Lattes: <http://lattes.cnpq.br/4017595982199951>. Endereço eletrônico: ariel5002@ hotmail.com

${ }^{2}$ Pós-doutor em Direito Público e Educação pela Universidade Nova de Lisboa-Portugal. Pós-doutor em Direito Civil e Processual Civil, Doutor em Direito e Mestre em Direito Processual, pela Universidad de Deusto-Espanha. Mestre em Educação pela PUC Minas. Professor do Mestrado Acadêmico em Direito Ambiental e Sustentabilidade na Escola Superior Dom Helder Câmara. Professor Adjunto da PUC Minas e Professor Titular licenciado da Faculdade de Direito Arnaldo Janssen. Advogado Sócio do Escritório Raffaele \& Federici Advocacia Associada. Integrante dos grupos de pesquisa: Regulação Ambiental da Atividade Econômica Sustentável (REGA)/CNPQ-BRA, Centro de Investigação \& Desenvolvimento sobre Direito e Sociedade (CEDIS)/FCT-PT e Núcleo de Estudos sobre Gestão de Políticas Públicas (NEGESP)/CNPQ-BRA. ORCID: <http://orcid.org/0000-0002-4711-5310>. Currículo Lattes: <http://lattes.cnpq.br/1638327245727283>. Endereço eletrônico: federici@ pucminas.br
\end{abstract}

Recebido em: 28/10/2016 - Aprovado em: 22/08/2017 - Disponibilizado em: 30/12/2017

\section{RESUMO}

O artigo compara o texto do anteprojeto da Comissão Afonso Arinos ao da Constituição da República de 1988 (CR/88) no que tange a proteção ambiental. Houve uma intensa participação para construção do texto final. A hipótese diz sobre a proteção mais eficaz da CR/88, tendo em vista a participação popular. Utilizou-se o raciocínio dialético, uma vez que estabeleceu uma tese (CR/88) e uma antítese (Comissão) para alcançar uma síntese, além de uma investigação jurídica na forma jurídico-comparativa. A hipótese foi parcialmente verificada. Houve um aprimoramento dos institutos de proteção, mas ocorreu uma importante supressão.

Palavras-chave: Proteção ambiental. Comissão Afonso Arinos. Institutos de proteção.

\section{THE CONSTITUTIONAL DEVELOPMENT OF THE ENVIRONMENTAL PROTECTION}

\section{ABSTRACT}

The article compares the draft text of Afonso Arinos Commission to the Constitution of 1988 (CR/88) with respect to environmental protection. There was intense interest for construction of the final text. The hypothesis says about the most effective protection of $\mathrm{CR} / 88$ with a view to public participation. We used the dialectical reasoning, since established a thesis (CR/88) and an antithesis (Commission) to achieve a synthesis, as well as a legal research on legal and comparative manner. The hypothesis was partially observed. There was an improvement of protection institutes, but there was a significant suppression.

Keywords: Environmental protection. Afonso Arinos commission. Protection institutes.

\footnotetext{
${ }^{1}$ Financiamento e Grupos de Pesquisas.
} 


\section{INTRODUÇÃO}

A Constituição da República de 1988 (CR/88) é considerada a Constituição Cidadã. Tal característica se deve a dois motivos principais: a presença dos institutos democráticos no corpo constitucional, contrapondo ao período anterior de exceção e a participação de diversos setores da sociedade da construção da norma.

Essa construção ocorreu a partir do texto da Comissão Afonso Arinos, em 1986 (CAA/86). Essa comissão reuniu pessoas de notável saber para a elaboração de um texto que serviria como base para os debates sociais. O resultado desses debates foi diferente do texto inicial. Assim, o trabalho visa comparar os dois textos e mostrar qual deles apresenta um nível maior de proteção ambiental.

A hipótese é que o processo de participação proporcionou uma melhora nos institutos de proteção ambiental, tendo em vista a organização de setores sociais afinados com a causa ambiental.

Foi utilizada concatenação jurídicosociológica como linha teórico-metodológica, uma vez que o fenômeno constitucional ultrapassa os limites do Direito. Prova disto é a participação de cientistas políticos, escritores, economistas e religiosos na Comissão Afonso Arinos.

O raciocínio usado foi o dialético, uma vez que comparou a tese $(\mathrm{CR} / 88)$, com a antítese (Comissão Afonso Arinos), chegando-se a uma síntese.

Como linha investigatória jurídica foi utilizado a jurídica-comparativa, levando em consideração a necessidade de comparar dois textos dentro do mesmo contexto social.

As duas obras fundamentais da pesquisa foram a CR/88 e CAA/86, tendo em vista a necessidade de comparação do texto inicial e da norma final. Todavia, para melhor compreensão dos temas tratados foram utilizadas obras específicas do tema, além do conjunto normativo temático.

$\mathrm{O}$ segundo capítulo tratou dos institutos arrolados no art. 225 da CR/88, fazendo uma correlação com diplomas normativos ordinários expedidos para a regulamentação. Além de traçar rapidamente um histórico da matéria ambiental em Constituições brasileiras.

O terceiro capítulo tratou do texto da Comissão de Afonso Arinos, promovendo uma ligação com o texto final, proporcionando um debate sobre os temas ambientais.

\section{INSTITUTOS DA CR/88}

A Emenda Constitucional (EC) $n^{0} 1$ de 1969 foi a primeira a incluir no corpo constitucional um termo relativo ao Direito ambiental e a proteção ambiental, o ecológico.

Tratava-se do art. 172: “art. 172. A lei regulará, mediante prévio levantamento 
ecológico, o aproveitamento agrícola de terras sujeitas a intempéries e calamidades. O mau uso da terra impedirá o proprietário de receber incentivos e auxílios do Govêrno" (BRASIL, 1969).

Ainda que tal dispositivo constitucional fosse anterior a Estocolmo1972, já se mostrava certo dever de cuidado com o meio ambiente. A norma obrigava o estudo prévio de determinadas áreas agrícolas sujeitas a ação massiva da natureza, e caso não fosse realizado, o dono da terra poderia ser penalizado pelo Governo. Trata-se de um dispositivo que não é capaz de proteger juridicamente o meio ambiente, todavia já se mostrava um avanço na causa ambiental em territórios brasileiros.

A CR/88 elevou as normas gerais do Direito ambiental ao patamar constitucional, promovendo uma ampla inserção dos temas nas vidas cotidianas dos cidadãos e na agenda do Poder Público e dos partidos. Isso propiciou um amplo debate sobre os temas ambientais, que antes eram praticamente ignorados. $\mathrm{O}$ art. 225 da $\mathrm{CR} / 88$ foi esse marco:
$\S 1^{\mathrm{o}}$ Para assegurar a efetividade desse direito, incumbe ao Poder Público: I - preservar e restaurar os processos ecológicos essenciais e prover $\mathrm{o}$ manejo ecológico das espécies e ecossistemas; II - preservar a diversidade e a integridade do patrimônio genético do País e fiscalizar as entidades dedicadas à pesquisa e manipulação de material genético;

III - definir, em todas as unidades da Federação, espaços territoriais e seus componentes a serem especialmente protegidos, sendo a alteração e a supressão permitidas somente através de lei, vedada qualquer utilização que comprometa a integridade dos atributos que justifiquem sua proteção;

IV - exigir, na forma da lei, para instalação de obra ou atividade potencialmente causadora de significativa degradação do meio ambiente, estudo prévio de impacto ambiental, a que se dará publicidade;

$\mathrm{V}$ - controlar a produção, a comercialização e o emprego de técnicas, métodos e substâncias que comportem risco para a vida, a qualidade de vida e o meio ambiente; (Regulamento)

VI - promover a educação ambiental em todos os níveis de ensino e a conscientização pública para a preservação do meio ambiente;

VII - proteger a fauna e a flora, vedadas, na forma da lei, as práticas que coloquem em risco sua função ecológica, provoquem a extinção de espécies ou submetam os animais a crueldade.

$\S 2^{\circ}$ Aquele que explorar recursos minerais fica obrigado a recuperar o 
meio ambiente degradado, de acordo com solução técnica exigida pelo órgão público competente, na forma da lei.

$\S 3^{\circ}$ As condutas e atividades consideradas lesivas ao meio ambiente sujeitarão os infratores, pessoas físicas ou jurídicas, a sanções penais e administrativas, independentemente da obrigação de reparar os danos causados.

$\S 4^{\circ}$ A Floresta Amazônica brasileira, a Mata Atlântica, a Serra do Mar, o Pantanal MatoGrossense e a Zona Costeira são patrimônio nacional, e sua utilização far-se-á, na forma da lei, dentro de condições que assegurem a preservação do meio ambiente, inclusive quanto ao uso dos recursos naturais.

$\S 5^{\circ}$ São indisponíveis as terras devolutas ou arrecadadas pelos Estados, por ações discriminatórias, necessárias à proteção dos ecossistemas naturais.

$\S 6^{\circ}$ As usinas que operem com reator nuclear deverão ter sua localização definida em lei federal, sem o que não poderão ser instaladas (BRASIL, 1988).

Trata-se de um artigo extenso da $\mathrm{CR} / 88$, que aborda inúmeras facetas do meio ambiente e do Direito ambiental. Possui seis parágrafos, sendo que o primeiro tem sete incisos. Importante notar que a matéria ambiental não está adstrita ao art. 225 da CR/88, outros dispositivos constitucionais são imprescindíveis para a interpretação constitucional do Direito ambiental.

O estudo neste momento demonstrará OS principais institutos contidos nos dispositivos do art. 225 da CR/88 e os desdobramentos legais.

\subsection{Caput}

A primeira oração já arrola o direito ao meio ambiente como um direito subjetivo (MACHADO, 2015, p. 147). Já foi alvo de inúmeros debates a questão de o direito ao meio ambiente não ser direito fundamental, uma vez que não se encontra no capítulo dos direitos fundamentais. Segundo Hupffer e Naime (2012) “a Constituição de 1988, principalmente no seu art. 225, faz uma clara opção pelo direito fundamental do indivíduo e da coletividade, consagrando a proteção ambiental” (HUPFFER; NAIME, 2012, p. 221-222).

Dentre as várias fundamentações se destacam duas. $\mathrm{O}$ direito ao meio ambiente é fundamental para a vida ${ }^{2}$ e a saúde ${ }^{3}$ humana, impossibilitando a separação dos institutos. Tal argumentação apresenta uma carga antropocêntrica. A outra tese refere-se à sistematização constitucional. Não é necessário um tópico exclusivo para os direitos fundamentais, estes estão espalhados

\footnotetext{
${ }^{2}$ Art. $5^{\circ}$ da CR/88. Todos são iguais perante a lei, sem distinção de qualquer natureza, garantindo-se aos brasileiros e aos estrangeiros residentes no País a inviolabilidade do direito à vida, à liberdade, à igualdade, à segurança e à propriedade, nos termos seguintes [...] (BRASIL, 1988).

${ }^{3}$ Art. $6^{\circ}$ da CR/88. São direitos sociais a educação, a saúde, a alimentação, o trabalho, a moradia, o transporte, o lazer, a segurança, a previdência social, a proteção à maternidade e à infância, a assistência aos desamparados, na forma desta Constituição (BRASIL, 1988).
} 
pela CR/88 e outros documentos ${ }^{4}$. Já está pacificado que o direito ao meio ambiente ecologicamente equilibrado é considerado um direito fundamental.

Nesta mesma oração tem-se a noção de meio ambiente ecologicamente equilibrado. Este instituto refere-se à manutenção da harmonia ecológica mesmo com a ação humana. Esta produz uma larga quantidade de intromissões positivas $\mathrm{e}$ negativas, assim o presente instituto tem o condão de orientar a ação a humana para garantir uma relação harmoniosa entre o meio ambiente e o ser humano.

A locução "bem de uso comum do povo" (BRASIL, 1988) é alvo de intensos debates sobre a natureza do bem ambiental. A posição majoritária defende tratar-se de bem difuso, isto é, toda a coletividade é titular do bem ambiental. Importante notar que o dano ambiental também apresenta características difusas, não é possível afirmar com total exatidão as vítimas de uma ação destrutiva ambiental, novos desdobramentos são constantemente descobertos, propiciando o conhecimento de outras vítimas.

Como dito anteriormente, o meio ambiente equilibrado é essencial para a vida humana e não-humana, sendo que a destruição da biosfera poderá levar a extinção da espécie humana. Reforça-se a ideia de direito fundamental essencial para a existência da vida e sociedade humana. Tal

\footnotetext{
${ }^{4}$ Tal hipótese está arrolada no art. $5^{\circ}, \S 2^{\circ}$ e $3^{\circ}$, da CR/88.
}

instituto tem a ideia de proteger a biosfera de intromissões que possam conduzir para uma extinção. Notadamente esse instituto tem um condão antropocêntrico, ocorre que do ponto de vista ético o ser humano não pode proporcionar uma vida degradante para os demais seres-vivos presentes na biosfera, especialmente os animais.

Após assegurar o direito ao meio ambiente, o art. 225 da CR/88 informa do dever de proteção do bem ambiental pelo Poder Público e pela coletividade. Por Poder Público entende-se o primeiro setor, o Estado. No caso brasileiro, todos os entes (União, Estados, Munícipios e Distrito Federal) têm responsabilidade na proteção do bem ambiental. Também têm o dever de proteção a Administração Direta e a Indireta (autarquias, fundações, empresas públicas e sociedades de economia mista). Já o termo coletividade engloba tanto o mercado, usualmente chamado de segundo setor, como o a sociedade civil organizada, o denominado terceiro setor. No limite, todas as pessoas naturais, jurídicas e entes despersonalizados têm o dever de proteger e preservar o meio ambiente. Trata-se de um dever universal. Essa obrigação tem uma vinculação com a característica difusa do bem ambiental, uma vez que se todos podem sofrer com condutas danosas, todos têm o dever de cuidar.

A última parte do caput diz a respeito ao caráter intergeracional. A presente geração deve garantir um meio ambiente para a 
geração futura. Trata-se de uma solidariedade intergeracional. A sustentabilidade de Machado (2015) exemplifica essa situação:

A noção r de
sustentabilidade funda-se
em pelo menos dois
critérios: primeiro, as
ações humanas passam a
ser analisadas quanto à
incidência de seus efeitos
diante do tempo
cronológico, pois esses
efeitos são estudados no
presente e no futuro;
segundo, ao se procurar
fazer um prognóstico
futuro, haverá de ser
pesquisado que efeitos
continuarão e quais as
consequências de sua
duração (MACHADO,
2015, p. 59).

Percebe-se que a atuação humana da geração atual não pode inviabilizar as gerações seguintes, a conduta deve ser sustentável. Essa parte do artigo está profundamente relacionada com a manutenção do equilíbrio ecológico. Sistemas desequilibrados tendem a insustentabilidade. Silva (2011) conclui sobre o tema debatido: “isso importa na imposição a toda a coletividade do dever de proteger e preservar o meio ambiente, bem como de buscar a sua reparação, de forma a manter a integridade do planeta" (SILVA, 2011, p. 119).

O caput do art. 225 da CR/88 é o núcleo duro do Direito ambiental brasileiro. Através dos dizeres do artigo, toda a conduta humana deve ser interpretada. Os parágrafos e os incisos seguintes passam a pormenorizar situações específicas.

\subsection{Primeiro Parágrafo e seus incisos}

O $\$ 1^{\circ}$ do art. 225 da $\quad \mathrm{CR} / 88$ proporciona efetividade ao caput através da obrigatoriedade da conduta estatal. Reafirma a qualidade do Estado como um condutor da proteção ambiental. Importante salientar que se trata de rol exemplificativo, o Estado não poderá se furtar de realizar outras atividades de proteção ambiental, alegando que não estão arroladas no art. 225.

$\mathrm{O}$ inciso $\mathrm{I}$, do $\S 1^{\circ}$, do art. 225 da $\mathrm{CR} / 88$, trata da preservação e recuperação dos ecossistemas e a promoção do manejo ecológico. A primeira parte pode ser considerada uma base da responsabilidade civil do Estado. Este deverá recuperar ecossistemas degradados para possibilitar o equilíbrio ecológico contido no caput. Importante ressaltar que a obrigação de recuperar também pertence ao particular nos casos específicos. Nota-se também que a ideia principal é preservar e caso ocorra algum dano, a tarefa é a recuperação. A segunda parte do inciso informa sobre o manejo ecológico. A Lei $\mathrm{n}^{\mathrm{o}}$ 9.985/00 diz no art. $2^{\circ}$, inciso VIII: "manejo: todo e qualquer procedimento que vise assegurar a conservação da diversidade biológica e dos ecossistemas" (BRASIL, 2000). Observa-se que são ações coordenadas de proteção ambiental. A mesma lei trata do Plano de Manejo, no art. $2^{\circ}$, inciso XVII: 
Art. $2^{\circ}$, inciso XVII, Lei ${ }^{\circ}$ 9.985/00. Plano de manejo: documento técnico mediante o qual, com fundamento nos objetivos gerais de uma unidade de conservação, se estabelece o seu zoneamento e as normas que devem presidir o uso da área e o manejo dos recursos naturais, inclusive a implantação das estruturas físicas necessárias à gestão da unidade (BRASIL, 2000).

Este plano visa estabelecer diretrizes para a proteção de determinadas áreas que possuem atributos específicos. O referido inciso está em total consonância com o caput do art. 225, uma vez que evidencia meio de promover um meio ambiente ecologicamente equilibrado.

O inciso II, do $\S 1^{\circ}$, do art. 225 da $\mathrm{CR} / 88$, trata do Biodireito e a biogenética. Tal campo de estudo tem sido explorado com grande magnitude, tendo em vista a potencialidade da manipulação genética. A primeira parte do inciso refere-se à proteção das espécies da extinção. O extermínio de uma espécie é uma violação constitucional, devendo o Estado promover a integridade do patrimônio genético brasileiro. A segunda parte atribui ao Poder Público o exercício do poder de polícia sobre entidade pesquisadoras do tema. O legislador infraconstitucional, na necessidade de regulamentar a matéria, expediu a Lei $\mathrm{n}^{\mathrm{o}} 11.105 / 05$, a Lei de Biossegurança. Essa lei regulamenta a questão dos organismos geneticamente modificados, além de estabelecer limites à atividade de manipulação genética. Entre esses limites está a criação do Conselho Nacional de Biossegurança, que tem a prerrogativa de formular e implementar a Política Nacional de Biossegurança.

$\mathrm{O}$ inciso seguinte (inciso III, do $\S 1^{\circ}$, do art. 225 da CR/88) trata da criação de unidades especiais de proteção. $\mathrm{O}$ meio ambiente deve ser protegido e preservado como um todo, contudo determinadas áreas apresentam atributos específicos que devem ser protegidos de forma mais rígida, tendo em vista a especialidade. Assim o inciso três proporcionou uma proteção constitucional para essas áreas. A lei ordinária que regula esse inciso é a já citada Lei n ${ }^{\circ}$ 9.985/00 - Lei do Sistema Nacional das Unidades de Conservação da Natureza (SNUC). A lei criou doze espécies de unidades de conservação, separados em dois gêneros. Essa variedade de enquadramentos acomoda uma proteção maior, já que a proteção será de acordo com as características do local. Marcon (2014) conclui sobre o tema Unidade de Conservação:

[...] consta a obrigação de definir espaços territoriais especialmente protegidos, o que se efetiva, sobretudo, pela criação de Unidades de Conservação, conforme se percebe pela própria ementa da Lei do SNUC, ao dispor que a mesma tem como função regulamentar, dentre outros dispositivos, o inciso III do $\S 1^{\circ}$ do artigo 225 .

Contudo, apesar dessas serem as expressões mais 
claras do cumprimento dessa exigência, enfatizase que a norma fixou como função definir espaços territoriais especialmente protegidos, e não apenas definir Unidades de Conservação (MARCON, 2014, p. 178).

A CR/88 criou uma família, que são os espaços territoriais especialmente protegidos. A Lei $n^{0}$ 9.985/00 informou sobre a existência do gênero Unidade de Conservação e as diversas espécies.

$\mathrm{O}$ inciso IV, do $\S 1^{\circ}$, do art. $225 \mathrm{da}$ CR/88, expressa o instituto do Estudo Prévio de Impacto Ambiental. Tal instrumento é essencial para mensurar os efeitos de determinadas atividades humanas ao meio ambiente ecologicamente equilibrado. Coroa os princípios da prevenção e da precaução na questão ambiental. Esta previsibilidade proporcionada pelo estudo é essencial para a elaboração de condutas capazes de mitigar ou compensar o dano. A depender do grau de impacto no meio ambiente, a atividade deve ser considerada inviável, impedindo assim sua realização. Ponto essencial no tema é a parte final do inciso, que garante a publicidade do estudo, ou seja, os interessados na proteção ambiental (Poder Público e coletividade) terão acesso ao estudo. Tal iniciativa promove o princípio democrático contido na $\mathrm{CR} / 88$. A possibilidade de o indivíduo conhecer o debate é ponto essencial, mas não exclusivo, para a participação democrática. $\mathrm{O}$ inciso seguinte (inciso $\mathrm{V}$, do $\S 1^{\circ}$, do art. 225 da
$\mathrm{CR} / 88$ ) informa sobre o poder de polícia da Administração Pública sobre eventuais atividades que possam promover danos ao equilíbrio ecológico. Este dispositivo guarda uma relação íntima com o inciso II, uma vez que este pode incluir atividade potencialmente danosa. Oliveira (2009) disserta sobre o tema:

[...] adotou como premissa
o reconhecimento dos
riscos à qualidade de vida
e ao meio ambiente
decorrentes das atividades
humanas, incumbindo-se
ao Poder Público o poder-
dever de "controlar a a
produção, a
comercialização e o
emprego de técnicas,
métodos e substâncias que
comportem risco para a
vida, a qualidade de vida e
o meio ambiente".
Consagrava-se, assim, o
princípio da precaução, no
inciso V do $1^{\circ}$ do artigo
225 do Texto
Constitucional, afeta à
biossegurança 2009, p.
(OLIVEIRA, 2009,
185).

O Estado tem o poder-dever de fiscalizar toda produção humana que possa potencialmente apresentar riscos a vida humana e ao equilíbrio do meio ambiente.

$\mathrm{O}$ inciso $\mathrm{VI}$, do $\S 1^{\circ}$, do art. 225 da $\mathrm{CR} / 88$, é mais uma parte da equação democrática. Além do acesso aos estudos de impacto ambiental, o indivíduo deve compreender o texto escrito. Essa compressão se dará através da escrita mais simples e principalmente da capacitação do indivíduo através da educação ambiental. Esta tem um caráter emancipatório do sujeito. O Poder 
Público é responsável pela promoção da educação ambiental dos indivíduos. $\mathrm{O}$ legislador ordinário, no exercício das atribuições, expediu a Lei $n^{0}$ 9.795/99, que dispõe sobre a Educação Ambiental e estabelece diretrizes. Tal diploma normativo deve ser interpretado junto com a Lei $n^{0}$ 9.394/96 que trata das diretrizes educacionais. Importante salientar que o ensino ambiental ocorrerá em todos os níveis educacionais ${ }^{5}$. Linhares e Piemonte (2010) alegam que a “educação não é um fim em si mesma; é, sobretudo, um direito fundamental e, portanto, instrumento chave para mudar valores, comportamentos e estilos de vida" (LINHARES; PIEMONTE, 2010, p. 106). A segunda parte do inciso trata da conscientização pública da questão ambiental. Essa obrigatoriedade visa à criação de inúmeros fiscais das atividades humanas. Garante-se, assim, uma proteção ambiental mais abrangente.

O último inciso (VII, do $\S 1^{\circ}$, do art. 225 da $\mathrm{CR} / 88$ ) discorre especificamente da proteção da fauna e flora. Estes são considerados vulneráveis frente à atuação humana, assim necessitam de um regime

\footnotetext{
5 Art. 9 ${ }^{\circ}$ Lei no 9.9795/99. Entende-se por educação ambiental na educação escolar a desenvolvida no âmbito dos currículos das instituições de ensino públicas e privadas, englobando:

I - educação básica:

a) educação infantil;

b) ensino fundamental e

c) ensino médio;

II - educação superior;

III - educação especial;

IV - educação profissional;

V - educação de jovens e adultos (BRASIL, 1999).
}

diferenciado de proteção. $\mathrm{O}$ inciso trata especificamente da extinção de espécies e condutas cruéis com os animais. A Lei $\mathrm{n}^{0}$ 9.985/00 traz essa proteção da fauna e da flora, através do estabelecimento de unidades de conservação e a Lei n ${ }^{0}$ 9.605/98 estabelece condutas penais para a proteção.

Como dito anteriormente o primeiro parágrafo e os incisos estabelecem condutas gerais para a atuação estatal. Os parágrafos seguintes também apresentam institutos relevantes para a proteção ambiental

\subsection{Demais Parágrafos}

$\mathrm{O} \S 2^{\circ}$ do art. 225 da $\mathrm{CR} / 88$ trata da responsabilidade civil do explorador de minério. A atividade minerária possui um elevado grau de impacto na natureza, a "abertura da cava, a mina a céu aberto implica a movimentação de toneladas de estéril e rejeito e a adução de grande volume de água, o que afeta a biodiversidade local e as comunidades próximas" (VIANA, 2015, p. 91). A atividade é notavelmente degradadora, contudo os minerais extraídos são essenciais para o modo de vida da sociedade, além disto a atividade gera riquezas para a localidade. Assim o dispositivo visa responsabilizar o explorador do minério pelo impacto ambiental. Tal medida respeita os critérios de justiça, como o explorador aufere o bônus da exploração, também deverá arcar com o ônus da recuperação ambiental. Salienta-se que a 
recuperação deverá ter contornos sociais, tendo vista o impacto social do fechamento de uma mina na economia local. $\mathrm{O}$ art. 225 da $\mathrm{CR} / 88$ como um todo oferece uma base principiológica de responsabilização da conduta danosa. Essa atitude visa garantir uma efetiva proteção ambiental. O parágrafo seguinte pode ser considerado o coração de base de responsabilização.

Esse parágrafo $\left(\$ 3^{\circ}\right.$, do art. 225 da $\mathrm{CR} / 88$ ) arrolou no ordenamento jurídico brasileiro a tríplice responsabilização e a possibilidade de responsabilização penal da pessoa jurídica. Informa que os causadores de dano ambiental são responsáveis penal e administrativamente pelos danos, além da necessidade de reparar os sinistros causados. Portanto, são responsáveis civil, penal e administrativamente. Essa necessidade de perseguição do dano ambiental decorre da característica difusa do bem. Como todos podem sofrer com os desdobramentos, o responsável deve arcar com isso, evitando assim uma socialização do custo do dano. Foi alvo de intensos debates a possibilidade de responsabilização da pessoa jurídica. $\mathrm{O}$ argumento contrário era a falta de consciência para cometer atos ilícitos. Contudo a tese foi derrotada e atualmente é possível a responsabilização. A pena deverá ser adequada, impedindo assim penas privativa de liberdade para a pessoa jurídica. Salientase que os administradores da empresa poderão

ser responsabilizados e estes poderão receber penas privativas de liberdade.

$\mathrm{O}$ dispositivo $\left(\$ 4^{\circ}\right.$, do art. 225 da $\mathrm{CR} / 88$ ) elenca a "Floresta Amazônica brasileira, a Mata Atlântica, a Serra do Mar, o Pantanal Mato-Grossense e a Zona Costeira" (BRASIL, 1988) como patrimônio nacional. Tal regime jurídico não desapropriou as terras particulares existentes nesses territórios, apenas colocou certas restrições para a utilização. É $\mathrm{O}$ respeito à função socioambiental da propriedade.

O $\S 5^{\circ}$, do art. 225 da $\mathrm{CR} / 88$, trata da indisponibilidade de determinados tipos de propriedade, tendo em vista o caráter imprescindível de proteção dos ecossistemas naturais e manutenção do equilíbrio ecológico. Essa característica de impossibilidade visa proporcionar uma preservação maior desses ecossistemas, uma vez que, dificultará qualquer atividade econômica potencialmente degradadora.

O último parágrafo do art. 225 da $\mathrm{CR} / 88$, o $\$ 6^{\circ}$, trata da questão nuclear. Informa que será necessária uma lei federal para delimitar o local de implantação das usinas nucleares. Tal atividade apresenta um grande risco à vida humana e ao meio ambiente em geral, contudo apresenta características interessantes:

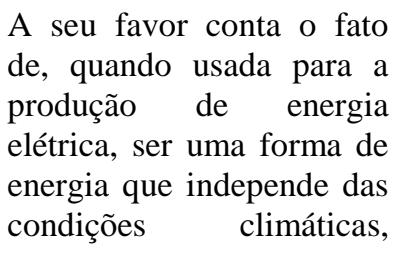




\begin{abstract}
impacta um território reduzido e não emite GEE ou outros gases que causam chuva ácida, poluição urbana ou diminuição da camada de ozônio. Além disso, as usinas nucleares podem ser construídas relativamente próximas aos principais centros consumidores, como ocorreu no Brasil, reduzindo as perdas energéticas e os impactos das linhas de transmissão (VIANA; TAVARES; LIMA, 2015, p. 147).
\end{abstract}

Mesmo apresentando qualidades, o risco de utilização dessa matriz é muito grande, assim coloca-se nas atribuições da União o manejo desse tipo energético.

\section{INSTITUTOS DO PROJETO DA COMISSÃO AFONSO ARINOS E SEUS ARTIGOS}

O texto da CAA/86 pode ser considerado um anteprojeto da CR/88. Foi apresentado em 1986 e alvo de intensos debates de diversos grupos sociais e atores diversos. $\mathrm{O}$ texto promulgado pela Assembleia Nacional Constituinte foi a já conhecida $\mathrm{CR} / 88$. A comissão era composta por pessoas notáveis nos mais diversos campos de estudos brasileiros. Foi chefiada por Afonso Arinos de Melo Franco. Dentre os notáveis pode-se citar o cientista político Bolívar Lamounier, o economista Celso Furtado, o religioso Guilhermino Cunha, o escritor Jorge Amado e os juristas José
Afonso da Silva, José Paulo Sepúlveda Pertence e Miguel Reale.

O texto constitucional apresentava 436 artigos e 32 artigos das Disposições Transitórias. A temática ambiental estava presente nos arts. 36, 74, inciso VII, 75, inciso XXI, 127, inciso V, 407 a 412. Assim como a $\mathrm{CR} / 88$, o tema ambiental transitou por diversos dispositivos, elencando uma porção para tratar o núcleo duro do tema. $\mathrm{Na} \mathrm{CR} / 88$ foi o Capítulo VI, do Título VIII e na CAA/86, o Título VIII, disperso em seis artigos.

É necessário ressaltar que o texto da CAA/86 tinha a seguinte redação no art. 36, elencado no Capítulo II, intitulado "Dos direito e garantias":

Art. 36 da CAA/86. Todos têm direito a meio ambiente sadio e equilíbrio ecológico, à melhoria da qualidade de vida, à preservação de paisagem e da identidade histérica da coletividade e de pessoa.

$\S \quad 1^{\circ}$. Garante-se ao consumidor a qualidade dos bens e serviços, a fiscalização da oferta, dos preços e da veracidade ia propaganda.

$\S 2^{\circ}$. É assegurada a legitimação do Ministério Público, de pessoa jurídica qualificada em lei e de qualquer do povo, para ação civil pública, visando à proteção dos interesses sociais a que se refere o presente artigo (BRASIL, 1986).

O debate sobre o direito fundamental ao meio ambiente seria completamente 
desnecessário, tendo em vista a construção tópica da CAA/86. Além disso, a melhoria de vida, o direito a paisagem e cultura dos povos. Outro ponto interessante é a legitimação do indivíduo ajuizar uma ação civil pública para a proteção desses direitos.

O núcleo duro refere-se ao art. 407 até 412, diversos temas são tratados nessa porção da CAA/86.

Informa o art. 407 da CAA/86:

Art. 407 da CAA/86. São deveres de todos e, prioritariamente, do Estado, a proteção ao meio ambiente e a melhoria da qualidade de vida.

Parágrafo único - $\mathrm{A}$ proteção a que se refere este artigo compreende, na forma da lei:

a) a utilização adequada dos recursos naturais;

b) o equilíbrio ecológico;

c) a proteção da fauna e da flora, especificamente das florestas naturais, preservando se a diversidade do patrimônio genético da Nação;

d) o combate à poluição e à erosão;

e) a redução dos riscos de catástrofes naturais e nucleares (BRASIL, 1986).

Inicialmente coloca-se como dever de todos a proteção ambiental, todavia coloca uma obrigatoriedade maior sobre o Estado. Essa obrigatoriedade maior poderia ser utilizada pelo particular como matéria de defesa na responsabilização ambiental. Outro ponto interessante do caput é a correlação entre proteção do meio ambiente e a melhoria da qualidade de vida. É evidente que o anteprojeto apresenta uma característica antropocêntrica, em maior grau que o texto promulgado.

O parágrafo único do art. 407 da CAA/86 informa o dever do legislador ordinário de editar leis sobre os temas arrolados. $\mathrm{O}$ rol apresenta caráter exemplificativo, uma vez que o anteprojeto não teria capacidade de esgotar as necessidades ambientais.

Os itens escritos nas alíneas apresentam correlação com os institutos da $\mathrm{CR} / 88$, tais como a proteção da fauna e flora. Em outros foram elaboradas leis sobre o tema, mesmo sem a obrigatoriedade da $\mathrm{CR} / 88$, citase a redução de catástrofes naturais e a Lei $\mathrm{n}^{\circ}$ $12.608 / 12^{6}$. Importante notar que a proteção do patrimônio genético é um tema recorrente, tendo em vista o caráter estratégico.

A redação do art. 408 da CAA/86 é:

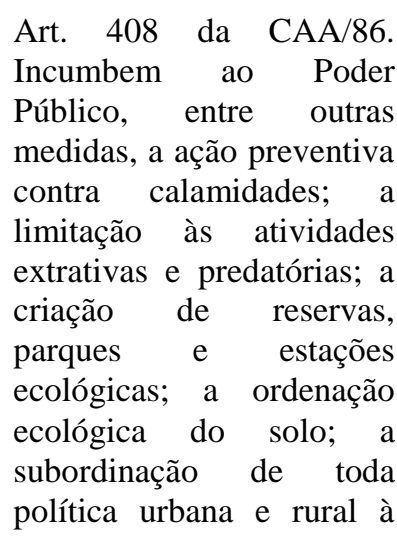

\footnotetext{
${ }^{6}$ Institui a Política Nacional de Proteção e Defesa Civil - PNPDEC; dispõe sobre o Sistema Nacional de Proteção e Defesa Civil - SINPDEC e o Conselho Nacional de Proteção e Defesa Civil - CONPDEC; autoriza a criação de sistema de informações e monitoramento de desastres; altera as Leis nos 12.340, de 1 o de dezembro de 2010, 10.257, de 10 de julho de 2001, 6.766, de 19 de dezembro de 1979, 8.239, de 4 de outubro de 1991, e 9.394, de 20 de dezembro de 1996; e dá outras providências (BRASIL, 2012).
} 
melhoria das condições ambientais; o controle das áreas industrializadas, a informação sistemática sobre a situação ecológica (BRASIL, 1986).

Assim como o texto final, foi destacada uma parte para os deveres do Poder Público na proteção ambiental. Relembra-se que esse tem uma obrigação especial de proteção.

Verifica-se que a CAA/86 tinha um especial apreço pela questão dos desastres ambientais. Outro ponto é obrigatoriedade de espaços territoriais distintos para a proteção de determinados ecossistemas. Também é necessário ressaltar a interpretação das políticas rurais e urbanas, através da questão ambiental. Não seria possível dissociar o desenvolvimento das cidades da questão ambiental. Ressalta-se ainda a obrigatoriedade de prestação de informações sobre a situação ambiental. Esse dispositivo atua no sentido de proporcionar um accountability vertical da temática ambiental. Pode-se relacionar esse dispositivo com a conscientização ambiental da CR/88.

Diz o art. 409 da CAA/86: “A ampliação ou instalação das usinas nucleares e hidroelétricas e das indústrias poluentes, suscetíveis de causar dano à vida ou ao meio ambiente, dependem de prévia autorização do Congresso Nacional” (BRASIL, 1986).

Talvez esse dispositivo seja o mais polêmico da CAA/86. Praticamente toda grande iniciativa deveria ter o crivo do
Congresso Nacional. Tal limitação poderia ser interpretada com uma total falta de livre iniciativa (art. 316, inciso II, CAA/86). Toda grande indústria deveria ter a autorização do Poder Legislativo federal. $\mathrm{O}$ texto final quedou-se apenas com as usinas nucleares.

Ensina o art. 410 da CAA/86: "e (sic) vedada no território nacional, na forma da lei, a prática de atos que afetem a vida e a sobrevivência de espécies, como a da baleia, ameaçadas de extinção" (BRASIL, 1986).

Esse dispositivo reforça o dever de proteção da fauna brasileira, citando um exemplo de uma espécie que na época estava ameaçada de extinção. Segundo o Ministério do Meio Ambiente as baleias ainda continuam na lista de espécies ameaçadas (BRASIL, 2008, p. 690). Informa:

As maiores ameaças às
baleias são o retorno da
caça comercial em águas
internacionais, se a
moratória for revogada,
seguida dos efeitos da
prospecção sísmica nas
rotas de migração e nas
áreas de reprodução e da
colisão com embarcações,
sem falar na poluição em
geral, que degrada os
ambientes marinhos
(BRASIL, 2008, p. 689).

A proteção da baleia não entrou ipsis litteris, no texto final. Nota-se que a proteção das espécies e do patrimônio genético tem um grande respaldo no texto da $\mathrm{CAA} / 86$, assim como no texto final da CR/88.

Está escrito no art. 411 da CAA/86: “A Floresta Amazônica é patrimônio 
nacional, Sua (sic) utilização far-se-á na forma da lei, dentro de condições que assegurem a preservação de sua riqueza florestal e de seu meio ambiente" (BRASIL, 1986).

Os debates da $\mathrm{CR} / 88$ proporcionaram um aumento dos ecossistemas considerados patrimônio nacional. Tal alargamento proporciona uma proteção mais efetiva do meio ambiente, uma vez que os terrenos incrustados nessas áreas possuem restrições que os demais terrenos não apresentam. Notase que o texto do dispositivo é bastante similar com o art. 225, $\$ 4^{\circ}$, da $\mathrm{CR} / 88$. A grande e essencial diferença foi a inclusão de outros ecossistemas no texto final.

O último artigo do Título VI (art. 412 da CAA/86) informa, "a lei definirá os crimes de agressão contra o meio ambiente" (BRASIL, 1986).

Ressalta-se a importante questão da responsabilização penal do agressor ao meio ambiente. $\mathrm{Na}$ redação final foram incorporados a responsabilidade administrativa e a civil, além da possibilidade de imputação penal para a pessoa jurídica.

Caso o referido dispositivo houvesse sido promulgado haveria uma discussão intensa sobre a impossibilidade de mais de uma responsabilização e do impedimento de discutir a responsabilidade penal da pessoa jurídica. A redação final do artigo proporcionou uma proteção ambiental mais efetiva e eficaz.

\section{CONSIDERAÇÕES FINAIS}

É difícil a comparação entre a CAA/86 e a $\mathrm{CR} / 88$. A primeira foi elaborada por uma pequena quantidade de pessoas para atender os mais diferentes aspectos abrangidos por um texto constitucional analítico. A segunda que levou em consideração o anteprojeto contou a participação de diversos setores da sociedade, milhares de proposições foram estudadas pelas mais diversas comissões parlamentares, além das inúmeras audiências públicas realizadas. A sociedade civil participou ativamente da construção do texto de 1988. Assim a chance de o texto final ter mais elementos de proteção ao meio ambiente é maior que o texto inicial.

A pesquisa verificou que o texto final apresenta melhor sistematização que o texto inicial. A redução de artigo se mostrou benéfica, além disso, a incorporação de parágrafos ao art. 225 da $\mathrm{CR} / 88$ propiciou uma interpretação junto o caput.

A CAA/86 tinha um ponto que, caso fosse agregado ao texto final, proporcionaria uma evolução do Direito ambiental de forma mais veloz. Caso fosse elencado no Título II da CR/88, "Dos direitos e garantias fundamentais", não haveria o debate intenso sobre o direito ao meio ambiente, passando para a fase posterior de evolução mais rapidamente.

Possivelmente, um dos grandes triunfos do texto final foi a tríplice 
responsabilidade e imputabilidade penal da pessoa jurídica. Caso esses temas não fossem alçados ao texto original da $\mathrm{CR} / 88$, dificilmente haveria a aplicação desses institutos. A defesa dos poluidores seria no sentido de impossibilidade de sanção sobre a mesma conduta no primeiro caso e no segundo a inexistência de consciência da pessoa jurídica, impossibilitando o dolo ou culpa do ente.

Outro ponto que o processo constituinte melhorou foi a obrigatoriedade de proteção ambiental. O texto inicial colocava o Estado como o principal responsável para o dever, sem eximir a coletividade. Contudo, tal disposição poderia ser utilizada para livrar o particular da proteção ambiental. O texto final colocou todos em posição de igualdade na proteção ambiental.

Também foi importante para proteção ambiental o aumento dos ecossistemas considerados patrimônio nacional. O texto inicial elencava apenas a Floresta Amazônica, já o texto final apresenta outros quatros biomas de proteção especial.

Um ponto polêmico foi a questão da autorização do Congresso Nacional para a instalação de hidroelétricas e indústrias potencialmente danosas. Nesse ponto é essencial a noção de equilíbrio entre proteção ao meio ambiente e o desenvolvimento econômico da nação. O texto final manteve apenas a questão nuclear, tendo em vista o potencial geométrico de dano ambiental.
O estudo prévio de impacto ambiental foi inserido no corpo constitucional no texto final. Tal instrumento é de notável importância para a proteção ambiental em solo brasileiro.

Conclui-se que, no geral o processo participativo que a CR/88 passou, proporcionou um texto mais completo na questão da proteção ambiental, salvo a exclusão tópica do direito fundamental ao meio ambiente dos direitos e garantias fundamentais.

\section{REFERÊNCIAS}

BRASIL. Anteprojeto constitucional (Comissão Afonso Arino). Anteprojeto Constitucional, elaborado pela Comissão Provisória de Estudos Constitucionais, instituída pelo Decreto n ${ }^{\circ} 91.450$, de 18 de julho de 1985. "Publique-se, inclusive com as palavras que tive a oportunidade de proferir por ocasião da entrega do anteprojeto da Comissão Provisória de Estudos Constitucionais. Ao Ministério da Justiça, para os fins previstos no Decreto $\mathrm{n}^{\circ}$ 91.450, de 18 de julho de 1985. Em 24 de setembro de 1986." Diário Oficial, Brasília, 26 set. 1986. Disponível em: <http://www.senado.leg.br/publicacoes/anais/ constituinte/AfonsoArinos.pdf>. Acesso em: 28 nov. 2015.

BRASIL. Constituição da República Federativa do Brasil, de 08 out. 1988. Diário Oficial, Brasília, 08 out. 1988. Disponível em:

<http://www.planalto.gov.br/ccivil_03/constit uicao/constituicaocompilado.htm>. Acesso em: 18 nov. 2015 .

BRASIL. Emenda Constitucional n ${ }^{\circ} 1$ de 17 out. 1969. Edita o novo texto da Constituição Federal de 24 de janeiro de 1967. Diário 
Oficial, Brasília, 20 out. 1969. Disponível

em:

<http://www.planalto.gov.br/ccivil_03/Constit uicao/Emendas/Emc_anterior1988/emc01-

69.htm>. Acesso em: 27 nov. 2015.

BRASIL. Lei n ${ }^{\circ}$ 9.605, de 12 fev.1998.

Dispõe sobre as sanções penais e administrativas derivadas de condutas e atividades lesivas ao meio ambiente, e dá outras providências. Diário Oficial, Brasília, 13 fev. 1998. Disponível em: <http://www.planalto.gov.br/ccivil_03/LEIS/ L9605.htm>. Acesso em: 18 nov. 2015.

BRASIL. Lei n ${ }^{0}$ 9.795, de 27 abr. 1999. Dispõe sobre a educação ambiental, institui a Política Nacional de Educação Ambiental e dá outras providências. Diário Oficial, Brasília, 28 abr. 1999. Disponível em:

<http://www.planalto.gov.br/ccivil_03/leis/19 795.htm>. Acesso em: 18. nov. 2015.

BRASIL. Lei $\mathrm{n}^{\circ}$ 9.985, de 18 jul. 2000. Regulamenta o art. 225, $\S 1^{\circ}$, incisos I, II, III e VII da Constituição Federal, institui o Sistema Nacional de Unidades de Conservação da Natureza e dá outras providências. Diário Oficial, Brasília, 19 jul. 2000. Disponível em:

<http://www.planalto.gov.br/ccivil_03/leis/19 985.htm>. Acesso em: 18. nov. 2015.

BRASIL. Lei $\mathrm{n}^{\circ}$ 11.105, de 24 mar. 2005. Regulamenta os incisos II, IV e V do $\S 1^{\circ}$ do art. 225 da Constituição Federal, estabelece normas de segurança e mecanismos de fiscalização de atividades que envolvam organismos geneticamente modificados OGM e seus derivados, cria o Conselho Nacional de Biossegurança-CNBS, reestrutura a Comissão Técnica Nacional de Biossegurança - CTNBio, dispõe sobre a Política Nacional de Biossegurança - PNB, revoga a Lei $\mathrm{n}^{\circ} 8.974$, de 5 de janeiro de 1995, e a Medida Provisória no $2.191-9$, de 23 de agosto de 2001, e os arts. $5^{\circ}, 6^{\circ}, 7^{\circ}, 8^{\circ}, 9^{\circ}$, 10 e 16 da Lei $n^{\circ} 10.814$, de 15 de dezembro de 2003, e dá outras providências. Diário Oficial, Brasília, 28 mar. 2005. Disponível em:
<http://www.planalto.gov.br/ccivil_03/_Ato2 004-2006/2005/Lei/L11105.htm>. Acesso em: 18. nov. 2015.

BRASIL. Lei $\mathrm{n}^{\mathrm{o}}$ 12.608, de 10 abr. 2012. Institui a Política Nacional de Proteção e Defesa Civil - PNPDEC; dispõe sobre o Sistema Nacional de Proteção e Defesa Civil SINPDEC e o Conselho Nacional de Proteção e Defesa Civil - CONPDEC; autoriza a criação de sistema de informações e monitoramento de desastres; altera as Leis $\mathrm{n}^{\mathrm{os}}$ 12.340, de $1^{\mathrm{o}}$ de dezembro de 2010, 10.257, de 10 de julho de 2001, 6.766, de 19 de dezembro de $1979,8.239$, de 4 de outubro de 1991, e 9.394, de 20 de dezembro de 1996; e dá outras providências. Diário Oficial, Brasília, 11 abr. 2012. Disponível em: <http://www.planalto.gov.br/ccivil_03/_Ato2 011-2014/2012/Lei/L12608.htm>. Acesso em: 18 nov. 2015.

BRASIL. Ministério do Meio Ambiente.

Livro vermelho da fauna brasileira ameaçada de extinção. Brasília: Ministério do Meio Ambiente, 2008. Disponível em: <http://www.mma.gov.br/estruturas/sbf2008_ dcbio/_publicacao/147_publicacao310320090 31646.pdf>. Acesso em: 28 nov. 2015. v. 2.

HUPFFER, Haide Maria; NAIME, Roberto. Vocação de diálogo do artigo 225 da Constituição Federal no conflito ambiental. Veredas do Direito, Belo Horizonte, v. $9, \mathrm{n}^{\mathrm{o}}$ 17, p. 213-243, jan./jul. 2012. Disponível em: $<$ http://www.domhelder.edu.br/revista/index. php/veredas/article/view/241>. Acesso em: 28 nov. 2015.

LINHARES, Monica Tereza Mansur; PIEMONTE, Márcia Nogueira. Meio ambiente e educação ambiental à luz do princípio da dignidade da pessoa humana. Veredas do Direito, Belo Horizonte, v. 7, $\mathrm{n}^{\mathrm{o}}$ 13/14, p. 101-124, jan./dez. 2010. Disponível em:

<http://www.domhelder.edu.br/revista/index. php/veredas/article/view/192>. Acesso em: 28 nov. 2015. 
MACHADO, Paulo Affonso Leme. Direito ambiental brasileiro. 23. ed. São Paulo: Malheiros, 2015.

MARCON, Victor Trevilin Benatti. A vinculação do poder público na criação de unidades de conservação. Veredas do

Direito, Belo Horizonte, v. 11, n 22, p. 175198, jul./dez. 2014. Disponível em:

$<$ http://www.domhelder.edu.br/revista/index. php/veredas/article/view/448>. Acesso em: 28 nov. 2015.

OLIVEIRA, Priscila Gonçalves. A juridicização dos riscos sobre os OGMs refletida no monitoramento pós-liberação comercial: o exercício do poder-dever estatal de controle sobre as atividades de risco positivado na Resolução Normativa CTNBio n. 5, 12 de março de 2008. Veredas do Direito, Belo Horizonte, v. 6, $\mathrm{n}^{\mathrm{o}}$ 12, p. 175 198, jul./dez. 2009. Disponível em: $<$ http://www.domhelder.edu.br/revista/index. php/veredas/article/view/169>. Acesso em: 28 nov. 2015.

SILVA, Marcela Vitoriano e. O princípio da solidariedade intergeracional: um olhar do Direito para o futuro. Veredas do Direito, Belo Horizonte, v. 8, $\mathrm{n}^{\mathrm{o}}$ 16, p. 115-146, jul./dez. 2011. Disponível em: $<$ http://www.domhelder.edu.br/revista/index. php/veredas/article/view/179>. Acesso em: 28 nov. 2015.

VIANA, Maurício Boratto. Panorama do setor mineral: legislação e impactos socioambientais. In: GANEM, Roseli Senna (Org.). Políticas setoriais e meio ambiente. Brasília: Câmara dos Deputados, 2015. p. 85130. Disponível em: <http://bd.camara.gov.br/bd/bitstream/handle/ bdcamara/21119/politicas_setoriais_ganen.pd f? sequence=1>. Acesso em: 28 nov. 2015.

VIANA, Maurício Boratto; TAVARES, Wagner Marques; LIMA, Paulo César Ribeiro. Sustentabilidade e as principais fontes de energia. In: GANEM, Roseli Senna (Org.). Políticas setoriais e meio ambiente. Brasília: Câmara dos Deputados, 2015. p.
131-176. Disponível em:

<http://bd.camara.gov.br/bd/bitstream/handle/ bdcamara/21119/politicas_setoriais_ganen.pd f? sequence=1>. Acesso em: 28 nov. 2015. 